\title{
¿Adónde vamos y de dónde venimos en Lingüística Aplicada? ${ }^{1}$
}

\section{(Where are We Going and Where have We Come from in Applied Linguistics?)}

Sherry E. Gapper ${ }^{2}$

Universidad Nacional, Costa Rica

\begin{abstract}
resumen
Se plantean analíticamente unas reflexiones sobre los orígenes de la Lingüística Aplicada, para asociarla a una concepción abarcadora y flexible de la disciplina. Se tratan problemas de diversa índole que parecen haber influido en el desenvolvimiento de las especialidades que la conforman. Se incorporan las dimensiones de espacio y de tiempo, junto a lo conceptual, para fomentar una visión integradora y unificadora, que favorezca el desarrollo actual y futuro de este universo del saber académico.
\end{abstract}

\begin{abstract}
The origins of Applied Linguistics are addressed analytically as a basis for a broad and flexible conception of the field. Different types of issues which may influence the diverse specialties comprising the field are discussed. Factors of time and space are included along with conceptual aspects, to foster an integrative and unifying view, and thus enhance current and future developments in this academic universe.
\end{abstract}

Palabras clave: LingüísticaAplicada, lenguaje, enseñanza de idiomas extranjeros Keywords: Applied Linguistics, language, foreign language teaching

$1 \quad$ Elaborado con base en la conferencia de apertura del IV Congreso Internacional de Lingüística Aplicada, llevado a cabo en mayo de 2013, en el Campus Omar Dengo, de la Universidad Nacional de Costa Rica. Recibido: 19 de agosto de 2012; aceptado: 3 de marzo de 2013

2 Escuela de Literatura y Ciencias del Lenguaje. Correo electrónico: sgapper@hotmail.com 
Empiezo por expresarles mi más cordial saludo de esta concurrencia, y en particular a quienes han tenido que viajar mucho, desde sus países, para acompañarnos hoy, así como a quienes se han tenido que desplazar desde otras regiones de Costa Rica para explorar el campo que nos une: la Lingüística Aplicada. Pero no solo «que nos une»; también debo decir que a veces nos separa, porque estamos ante un campo con múltiples manifestaciones, y que ha llevado, y no en pocas ocasiones, a debates sobre su definición y su función. Por supuesto, en Costa Rica se han dado esas discusiones, y deben seguirse dando, porque es lo que verdaderamente enriquece y dinamiza su desarrollo.

Estamos en el cuarto congreso de esta índole en la relativamente breve historia de la Escuela de Literatura y Ciencias del Lenguaje, de la Universidad Nacional de Costa Rica, fundada ya hace cuarenta años, y levantada en parte sobre los programas heredados de la antigua Escuela Normal Superior. Pensemos en lo que hoy hemos llegado a ser: contamos con la presencia de profesionales de muy variadas procedencias y de diversas instituciones educativas costarricenses, situación que favorece y fomenta un examen profundo de lo que hacemos cotidianamente como docentes. ¿Cuál es, hoy día, nuestro papel en ese gran conjunto de temas que constituyen la Lingüística Aplicada?, ¿cuál podría ser el del futuro?

Se suele especular, de manera general, sobre los orígenes de la Lingüística Aplicada. Se habla de épocas o momentos, mencionan pioneros o fundadores, etc. Conocemos bien lo que dictan los textos especializados de nuestros días, pero por ahora preferiría que nos retásemos aquí a dudar de esos datos que leemos: dejemos de lado, aunque sea durante estos cuarenta minutos que me han dado, nuestra historia inmediata que a veces nos constriñe, sobre todo en este llamado «nuevo mundo», donde nuestra historia la constituye un surtido de historias a veces desconocidas y por ello mismo olvidadas. Afirmar que la Lingüística Aplicada la fundó un determinado grupo de especialistas o estudiosos, marca probablemente un útil punto de 
partida para su historia y para su desarrollo reciente, pero llega a restringir nuestra visión de los orígenes de nuestra disciplina, y todo lo que alberga. Incluso podría limitarnos en nuestras exploraciones de lo que debería lograrse en el futuro, a corto o mediano plazos. Pensemos más ampliamente en los estudios de las lenguas y en los hechos asociados al lenguaje, para incrementar nuestra libertad de análisis.

Por estar inmersos en la complejidad de nuestras propias circunstancias históricas, podemos tentarnos a menospreciar el valor - ¡incluso la existencia! - de los saberes alcanzados en otras épocas, o de simplificar logros y avances. Esta actitud podría atribuirse al desconocimiento, tal vez, pero también a otros motivos: conveniencia, creencias, razones políticas o comerciales, o a un exceso de trabajo que nos impide actuar más allá de nuestras urgencias cotidianas. Corremos a menudo el riesgo de aislarnos en el trabajo, de aislarnos en el espacio, de aislarnos en el tiempo, de aislarnos entre personas, no tanto por individualismo, sino por una especie de sobreespecialización, autosuficiencia o necesidad.

Midamos, aquí y ahora, lo que les planteo: repensar un poco lo que podría ser la Lingüística Aplicada en cada una de nuestras instituciones, con una base tal que nos lleve a rebasar ampliamente los cotos del espacio y del tiempo de nuestra disciplina. Para elegir el título de esta breve conferencia, acudí a un conocido poema de Rubén Darío, «Lo fatal», que seguramente muchos aquí conocen o habrán leído en tiempos colegiales; aquel que empieza diciendo «Dichoso el árbol que es apenas sensitivo, y más la piedra dura porque esta ya no siente...», etc. Tal vez ya lo recuerdan, o les resulta familiar ese principio; pero he preferido quedarme con los versos finales, llenos de melancolía y misterio, que vienen muy bien para el tema que les quiero ofrecer en esta mañana; el poema se cierra con solemne incertidumbre, así: « iy no saber adónde vamos ni de dónde venimos!»³.

3 Rubén Darío, ET poema «Lo fatal» cierra el libro Cantos de vida y esperanza, publicado en 1905. Tomado de Rubén Darío, Poesías completas. Edición, introducción y notas de A. Méndez Plancarte (Madrid, Aguilar, 1968) 688. 
Retomaremos esos célebres versos citados, más adelante. Por lo pronto, dejemos provisionalmente de lado lo convencional, lo que hayamos memorizado, lo que suele decirse en cuanto a los orígenes de la Lingüística Aplicada, para situarnos allende los confines de nuestro modo habitual de abordar y valorar este campo de estudios. Partamos de una aproximación, si no completa, cuando menos abarcadora e integradora, abierta y flexible, desprendiéndonos de las ataduras que nos impiden el movimiento o el cambio; es decir, la dinámica obligada que nos ofrece la historia.

Entre los que estamos aquí, muchos se dedican a formar profesionales cuya vida laboral se extenderá, muy posiblemente, entre 2010 y 2060; tal vez más. El sitio web de la University of Southern California indica que los estudiantes que ingresarán este año tienen unas expectativas de vida de cien años, y ejercerán su profesión durante buena parte de ese transcurso. Y les pregunto ahora: ¿tenemos, de veras, conciencia de estar formando a estudiantes que deben afrontar los desafíos (muchos desconocidos ahora mismo) de los próximos cincuenta años? En Costa Rica, es habitual la creencia — casi siempre plasmada en la prensa - de que como educadores debemos atender las necesidades del mercado laboral. Pero para el mercado actual, ya todo esfuerzo que se haga es tardío, casi extemporáneo. Mediante sus diversas áreas del saber, las universidades contemporáneas - y prefiero referirme por lo pronto a las públicas o estatales - deberán construir, o por lo menos proyectar, una nueva realidad en la que interactuarán los profesionales que actualmente formamos.

Como dice el poema de Darío, apenas sospechamos lo que ocurrió en el pasado y apenas sospechamos lo que puede ocurrir en el futuro. Tal es nuestra situación. Cierto: desconocemos el futuro pero tenemos la obligación de emprender ciertas tareas, cuyo valor o posibilidades apenas intuimos. Lo concreto en una idea: en la actualidad se realizan en ciertos países desarrollados estudios sobre el cerebro humano: me refiero a dos en particular, constituidos en verdaderos megaproyectos: uno, el Human Brain Project (HBP), en 
Europa; otro: el BRAIN (conocido en español como la «iniciativa cerebro»). No hay duda alguna de que sus resultados revolucionarán muchos campos de estudio, en particular el nuestro, dada la información que se espera extraer sobre la estructura y el funcionamiento del cerebro humano, y en particular el de la memoria. Se habrán comprobado algunas de nuestras conjeturas (es decir, lo que actualmente enseñamos sobre el cerebro y la adquisición de lenguas, que de por sí se desactualiza muy rápido), o bien se habrán corregido y mejorado.

El proyecto Human Brain Project ${ }^{4}$, ya en su segunda fase, tiene como objetivo principal desarrollar una simulación detallada del funcionamiento del cerebro humano, integrando datos de distintos tipos (anatómicos, electrofisiológicos, histológicos y químicos), que se han logrado recopilar mediante de nuevos instrumentos tecnológicos. Ya será necesario estudiar durante los años venideros las implicaciones que esto puede tener para la Neurolingüística y para la Lingüística Aplicada en cualquiera de sus manifestaciones.

Con el mencionado proyecto de neurociencia, Brain Research Through Advancing Innovative Neurotechnologies ${ }^{5}$, sus responsables se han propuesto elaborar un mapa detallado del cerebro humano, con atención en las conexiones que tienen lugar durante el pensamiento; al mismo tiempo están elaborando instrumentos para llevar a cabo los estudios necesarios para lograrlo. Esto significa que para la Lingüística Aplicada se podrá contar con una base física de los procesos activados al emplear o adquirir un idioma.

Proyectos como los mencionados muestran que durante la «vida laboral» de quienes se forman actualmente, los lingüistas ya no dependerán tanto de la observación de resultados de experimentos para luego inferir qué podría haber ocurrido en el cerebro; antes bien, contarán con una base de conocimientos más sólida referida del cerebro humano para los distintos procesos de

$4 \quad$ Human Brain Project, http://www.humanbrainproject.eu; consultado el 1 de mayo de 2013.

5 National Institutes of Health, «Brain Research Through Advancing Innovative Neurotechnologies (BRAIN) Initiative», <http://www.nih.gov/science/brain>; consultado el 1 de mayo de 2013. 
intervención, tales como la enseñanza de una lengua extranjera o materna o la terapia del lenguaje.

Desconocemos cuál podría ser el desarrollo, en vista de la cantidad de variables que pueden influir en el proceso. Tendremos, sí, que ajustarnos a esos nuevos conocimientos; pero también — no lo perdamos de vista - estamos obligados a conocer lo que ha acumulado, a nuestro favor, el pasado. Sin embargo, podemos afirmar que apenas sospechamos lo que ha transcurrido en siglos anteriores en cada una de las disciplinas que han aportado a las especialidades reunidas en la noción de lingüística aplicada. Nos conviene, amigas y amigos colegas, averiguar también de dónde venimos, aunque Darío no lo supiese en su poema.

Pasemos a considerar las definiciones habituales de nuestra disciplina. No se trata de empezar a citar ni comentar aquí las diversas definiciones, abarcadoras o excluyentes que encontramos, sino dar un paso más para sacar algo en claro de este complejo debate. Hay autores que se refieren a la lingüística aplicada y otros a aplicaciones de la lingüística. Podemos nombrar a Brumfit, a Cook, a Corder, a Davies, a Kaplan, a McCarthy o a Widdowson, pero apenas son unos pocos. Hay cientos o miles de especialistas que se han ocupado del asunto. Algunos resaltan su papel en la enseñanza de idiomas, en las teorías de la adquisición de idiomas y en los principios pedagógicos. Muchos añaden otros campos como el planeamiento lingüístico, la sociolingüística, la psicolinguística, la terapéutica del lenguaje, la linguiística forense, la traducción y la interpretación, la lexicología y la terminología, el binomio lengua y cultura, o bien lo atinente a aspectos sobre regiones culturales y lingüísticas. Los conceptos varían de país en país, o de corriente en corriente, pero tienen rasgos en común: todas las definiciones aceptan que en la Lingüística Aplicada interviene al menos una combinación de aspectos teóricos y prácticos del lenguaje.

Son abundantes, como ustedes lo suponen bien, los debates sobre este asunto, en la comunidad académica internacional, incluida la nuestra costarricense. Entre las lecciones que nos han dejado esos debates 
está la certeza de que muy poco se avanza con restringir el campo, cuando hay tanto que aprender si se saca provecho de lo que hay en común, y así enriquecer los estudios en una actitud de reciprocidad.

¿Podría, entonces, afirmarse que antes de 1920, 1940 o 1960, nadie se había referido a problemas del lenguaje? Por supuesto que sería absurdo, estimables colegas, si se tiene en cuenta que hay nutrida noticia de escritos sobre estos temas desde hace cinco o más centurias. Veamos estos ejemplos que tengo a mano: una definición escrita en inglés alrededor de 1620, por un brillante pensador: «A consonant is a letter symbolizing a sound articulat that is broken with the tuiches of the mouth ${ }^{6}$ ». Literalmente: «Una consonante es una letra que simboliza un sonido articulado que se interrumpe con los movimientos de la boca». Alexander Hume, su autor, elaboró ese escrito en un momento de mucha producción referida a la lengua inglesa. Otro ejemplo: Ben Jonson redactó un texto sobre la gramática de la lengua inglesa (1640), dos siglos después de los cambios acaecidos en esa lengua por influencia del francés; una reacción ante la invasión de otra lengua, muy parecida a la que hoy se da en el caso del español, con respecto al inglés. Ambos intelectuales consideraron el valor comunicativo de los elementos que describían. El manuscrito de donde se tomó la cita anterior, «Of the Orthographie and Congruitie of the Britan Tongue», se conserva en el Museo Británico; lo publicó de nuevo en 1865 la Early English Text Society, como parte de un esfuerzo por difundir y conservar lo escrito sobre la lengua inglesa. ¿Planeamiento lingüístico? Desde tiempos casi inmemoriales de nuestra historia, han existido estudios parecidos a los que catalogamos hoy como Lingüística Aplicada, pero para nosotros, es solo con el desarrollo tecnológico actual que ha sido posible volver a antiguos textos como éste para complementar nuestra visión de la evolución de nuestro campo, y fortalecer las bases que por lo general, solo sospechamos.

6 Alexander Hume, «Of the Orthographie and Congruitie of the Britan Tongue» (1620?), (Londres: Early English Text Society, 1865) 12. 
Cito de nuevo: «The nether lip stryking on the overlip makes $b$, $m$, $p$, and on the teeth it makes $f$ and $v{ }^{7}$. Es decir: «Para pronunciar la $b$, la $m$ y la $p$, el labio inferior toca el labio superior; y para pronunciar la $f$ y la $v$ (uve), [el labio inferior] toca los dientes». Se referían con toda precisión a los lugares y modos de articulación. Estos textos, que uso como ejemplo, podrían ser tomados como extractos de algún famoso experto contemporáneo, representante de una de las ramas de Lingüística Aplicada; pero no es así: son de otra época y utilizan otros términos. En otras partes del mismo tratado que empleo para ejemplificar, hay referencias a la pronunciación de las vocales, los diptongos, la sílaba y la acentuación; y a la pronunciación de los distintos dialectos del inglés. Incluso, hay un breve estudio comparativo de la pronunciación de los sonidos (fonemas, aunque aún no se usaba ese término) con los del francés, del latín y del griego. Son conocimientos que algún incauto pensaría que proceden solo de avanzados tratados contemporáneos. Un aspecto esencial que podemos ilustrar por medio de este ejemplo es cómo los términos empleados en una época u otra para referirse al mismo fenómeno llevan a pensar que se trata de algo distinto y dificultan la continuidad de un campo de estudio, o bien la comparación de conocimientos descritos en distintas épocas.

Prosigamos en esta exploración, centrándonos en otros factores; uno de ellos, el relacionado con los artículos que se redactan, las revistas que los publican, los libros que se elaboran, las casas editoriales que los comercializan; indaguemos a partir de los temas de los congresos; a partir de los contenidos de programas y asignaturas preferidos en las universidades formadoras de nuevos profesionales; y a partir de la investigación académica que se promueve. Ello nos da una idea sobre lo que se entiende, en la actualidad, por Lingüística Aplicada.

Veamos el caso de las revistas académicas universitarias. En un vistazo preliminar se localizaron 250 revistas académicas especializadas autodefinidas como «revistas de Lingüística Aplicada». Al observar los

7 Hume, 12. 
descriptores de cada una, es evidente la amplitud de temas que abarcan $\mathrm{y}$, en consecuencia, palpable la estrechez desde la cual se valora nuestra disciplina. Una búsqueda preliminar en uno de los directorios de revistas de acceso abierto (Directory of Open Access Journals ${ }^{8}$ ) arrojó revistas especializadas publicadas en distintas lenguas y en países tan diversos como Alemania, Brasil, Australia, Canadá, Chile, España, Finlandia, Francia, Hungría, Indonesia, Lituania y muchosotros.

Pasemos a las casas editoriales. Al menos setecientas casas editoriales publican estudios, libros de texto, enciclopedias, diccionarios, revistas especializadas, libros de referencia y otros materiales propios de la Lingüística Aplicada. Si analizamos las políticas editoriales, encontramos muchas opciones y algunas diferencias. Resultaría imposible en este momento ofrecerles siquiera una muestra representativa, pero en conjunto esas casas editoriales, con sus políticas editoriales y comerciales, definen en gran parte nuestro campo de estudio ya que mucho se comunica por medio de los materiales que publican.

Por otro lado, una somera búsqueda indica que hay casi cincuenta asociaciones de Lingüística Aplicada distribuidas en todos los continentes, ocupadas en muy diversos asuntos lingüísticos según el entorno particular en cada caso. Pensemos en las diferencias y similitudes en cada caso. Podríamos señalar, en primer lugar, una asociación internacional que busca reunir estas diversas concepciones, como una especie de punto de encuentro. Y luego hay otras como la Asociación Mexicana de Lingüística Aplicada, la brasileña, la latinoamericana, la canadiense y varias de los Estados Unidos; también las hay en Europa, en Latinoamérica, y en lejanos países para nosotros, de Asia, África y Oceanía, que se centran un poco más en sus situaciones particulares. Los diversos entornos lingüísticos, políticos y culturales de la asociación de Israel, de Japón, de Grecia o de Australia, por ejemplo, enriquecen el campo y proporcionan nuevas formas de abordar un estudio. Pensemos en las características culturales y lingüísticas de estas

8 Directory of Open Access Journals, <http://www.doaj.org>; consultado el 1 de mayo de 2013. 
regiones que tanto tienen que aportar a la Lingüística Aplicada. Con frecuencia enfrentamos problemas comunes y al manifestar apertura hacia nuestras especialidades podemos retomar las experiencias que nos permiten buscar nuevas soluciones.

Construyamos nuestra definición desde la perspectiva de las universidades y centros especializados de investigación. Desde luego, abundan instituciones de enseñanza superior que han realizado estudios sobre aspectos asociados con el lenguaje, desde hace muchos años y en todo el mundo. Lo que ahora se conoce como la Lingüística Aplicada, tiene sus raíces y ramificaciones en muchas partes del mundo. Las investigaciones que se realizan, los programas y los cursos que se ofrecen, sobre los problemas lingüísticos elegidos por unos y otros, todos en conjunto definen nuestro campo. Eso es lo que existe y lo que nos define.

Si pasamos a considerar cómo se manifiesta el campo de Lingüística Aplicada en los congresos que se ofrecen y en otras formas de organización, tomamos verdadera conciencia de lo variado que es el campo. Empezando por casa, los cuatro congresos del CILAP se han ofrecido para que en Costa Rica haya oportunidad de conocer otras experiencias del ámbito internacional y de difundir lo que se desarrolla en nuestro medio académico particular. Para este IV CILAP, los organizadores decidieron limitarlo a ciertas áreas, como ya ustedes se habrán percatado: 1. la adquisición y aprendizaje de lenguas extranjeras; 2. los estudios sobre traducción; 3. los lenguajes especializados; 4. las políticas lingüísticas y la ética; y 5. la lingüística aplicada a áreas específicas. Y al definir cada una de estas áreas hubo que incluir (¡y también excluir!), aspectos afines o relacionados. Esta y otras convocatorias nos ayudan a conocer diversas concepciones de la LingüísticaAplicada.

Dejando por un momento el caso de Costa Rica, en la ocasión en que consultamos Linguist List $^{9}$, una especie de foro internacional en que se dan a conocer actividades asociadas a la linguística, la literatura y a los estudios del lenguaje en todo el mundo, nos enteramos

9 Linguist List, «Calls and Conferences»: 〈http://linguistlist.org/callconf〉; consultado el 1 de mayo de 2013. 
de más de 753 congresos y talleres anunciados para el presente año y los primeros meses de 2014 (incluidos unos 125, como el nuestro, solo para el mes de mayo de 2013).

Hay también un conjunto de aspectos de índole ética, por calificarla de algún modo, que influyen en el desarrollo de nuestra área de conocimientos. Colegas de distintas universidades se han referido al problema de las rivalidades entre distintos departamentos, entre distintos centros de investigación, o entre especialistas. Es común encontrar divisiones entre áreas de estudio que más bien tienen mucho que compartir entre sí. En el caso de la Universidad Nacional, la estructura de la Escuela de Literatura y Ciencias del Lenguaje facilita la interacción entre especialidades de campos afines, al agrupar en una sola unidad académica la lingüística, la literatura, la enseñanza de idiomas extranjeros (tanto las lenguas mismas, como su proceso de enseñanza), la traducción y el estudio de las lenguas indígenas. En otras universidades se encuentra separada la lingüística de los estudios de la lengua materna, o bien el estudio de la literatura de la lengua materna aislado del estudio de las lenguas extranjeras. Esta ventaja estructural y funcional que ofrece la Escuela de Literatura y Ciencias del Lenguaje la deberíamos aprovechar mucho más. Estos nexos permiten enriquecer nuestro trabajo especializado al poner en práctica conocimientos de otros campos, y a darnos cuenta - a tiempo- que lo que estamos proponiendo ya se hizo en un campo afín.

Como ejemplo está el que la traducción y la interpretación forman una de las áreas de la Lingüística Aplicada; han quedado incluidas en el presente congreso, y esto nos lleva a preguntarnos: ¿cuál es la razón por la que a veces, y en otros lugares, quedan excluidas? En distintas universidades se encuentran separaciones entre el Departamento de Lenguas Romances (español, portugués, francés, italiano), en los que se estudian sus lenguas, sus culturas y sus literaturas, y el Departamento de Inglés (en que se estudia la literatura escrita en inglés), y además encontramos otras divisiones esenciales entre esos departamentos y el Departamento de Lingüística. 
Hace tan solo unos días, la rectora de una de las sedes de la Universidad de California se refirió a la libertad académica en los siguientes términos:

Una universidad se reconoce como tal porque por definición ofrece un menú integrador o más bien un universo de áreas de investigación y perspectivas teóricas. (...) La experimentación, el pensamiento crítico y las pruebas constantes de ideas con una apertura para la revisión son componentes críticos del proceso universitario. Buscamos trascender las interpretaciones ideológicas o políticas de los fenómenos, y las controversias sobre las políticas públicas (...) Al personal académico universitario también se le da otro derecho y responsabilidad: la libertad académica. La libertad académica protege a un miembro de su claustro de represalias, en caso de que sus investigaciones no sean ortodoxas o políticamente populares. Esta garantía es vital para fomentar la innovación. Consideremos algunos ejemplos históricos (y actuales) de intelectuales que fueron encarcelados, amenazados o despedidos por proponer nociones radicales como el hecho de que el sol era el centro del sistema solar, o el sufragio universal y la participación cívica, o por buscar múltiples explicaciones por los orígenes de la vida en nuestro planeta o por exploraciones de sistemas económicos distintos o perspectivas religiosas de minorías ${ }^{10}$ (traducción de S. G.).

Aquella funcionaria planteó una inquietud que compartimos en nuestras instituciones. Un congreso como éste nos abre ese espacio

10 Texto original: «A university is called a university because it is designed to have a comprehensive menu or a universe of scholarly areas and theoretical perspectives. (...) Experimentation, critical thinking and constant testing of ideas with openness to revision are critical components of the scholarly process. We strive to transcend ideological or political interpretations of natural phenomena or public policy controversies. (...) University faculty are also granted an additional right and responsibility - academic freedom. Academic freedom protects a faculty member from retribution if her or his research is unorthodox or politically unpopular. This guarantee is vital to nurture innovation. Consider historical (and current) examples of intellectuals who were jailed, threatened, or fired for proposing such radical notions as the sun being the center of the solar system, universal suffrage and civic participation, multiple explanations for the creation and development of life on earth, or explorations of unpopular economic systems or minority religious views» (tomado de un mensaje de difusión, del 28 de marzo de 2013). 
de libre discusión; permite afirmar nuestro derecho de disentir y de abordar los temas de estudio desde diversas perspectivas. Nos recuerda que aun en especialidades como la nuestra, existen variadas aproximaciones teóricas válidas, y también existen las oficiales, las institucionales, las de moda, las apoyadas por imperativos comerciales, y las vigentes en determinada época. No podemos excluir a un colega o a una investigación por corresponder a otra corriente metodológica, ni apartar a alguien porque no necesariamente sabe, o no sabe, lo mismo que nosotros. No podemos excluir a alguien por contar con una formación diferente o experiencia laboral distinta. Desconocer una corriente teórica, cuando se tiene conocimiento de otras, no es razón para discriminar o excluir.

Por razones financieras principalmente, en muchas instituciones se han establecido procedimientos a los que el cuerpo académico debe acatar. Lo que en principio parece ser una medida apropiada esto es, proteger la subvención de las investigaciones más valiosas y organizarse según prioridades institucionales - puede convertirse, a fin de cuentas, en un riesgoso procedimiento de acción institucional. Puede llegar a restringir el ejercicio académico de la investigación de muchas maneras: en casos como estos quienes investigan tienen que producir precisamente lo que se «prometió» en la formulación inicial del proyecto, y hasta excluir forzadamente los eventuales hallazgos o nuevas direcciones que la misma investigación fue propiciando. Es decir, que si se da con nuevos caminos, no tendrían mayor importancia, porque lo que se podría validar o legitimar sería solo aquello que se proyectó al principio del recorrido. Como ven, no siempre la ciencia corre pareja con la administración institucionalizada. Queda en entredicho, tan solo para mencionar un factor, la creatividad y la inventiva, desde el punto de vista intelectual y científico.

En nuestras discusiones referidas a la sobreespecialización o bien a la afinidad o exclusión de ciertas áreas en determinado momento, o a la pertinencia de un área de conocimientos particular (como lo es, para nosotros, la Lingüística Aplicada), tengamos en 
cuenta también que a lo largo de la historia ha variado mucho la manera de agrupar las áreas de conocimiento. Actualmente en nuestras universidades no solemos encontrar una Escuela de Música en la Facultad de Ciencias Exactas junto con la Matemática y la Física. Antes se asociaban y siguen teniendo importantes aspectos en común. En este congreso, por ejemplo, se estimó poco viable incluir estudios literarios pese al papel fundamental que tiene en la enseñanza del español como segunda lengua en otros países.

¿Qué idea de la Lingüística Aplicada conviene entonces, aquí y ahora: ¿la que se puso en práctica al fundarse esta nuestra universidad hace cuarenta años?; ¿la que se ha desarrollado a lo largo de siglo xx en los Estados Unidos?; ¿la que ha empleado y en cierta medida construido cada uno de nosotros a partir de cierta formación y experiencias particulares? ¿No convendría abrirnos a todas las disciplinas y subdisciplinas afines (y a veces no tan afines) para enriquecer lo que estamos haciendo. ¿No nos convendría buscar relaciones insospechadas, más que poner límites?

Pese a la existencia de abundante bibliografía sobre la historia de nuestros países y el desarrollo de nuestras lenguas y culturas, o incluso sobre la enseñanza de lenguas, como A History of English Language Teaching o el más abarcador Twenty-Five Centuries of Language Teaching ${ }^{11}$, persiste una acentuada tendencia a la concentración en la época actual y en Occidente. Puede que por conveniencia académica y cultural, hemos creado nuevos puntos de partida, cada vez más limitados y menos variados, que aunque hayan resultado útiles, también han dejado en el olvido conocimientos de épocas anteriores.

¿Y el papel y valoración actuales de los nuevos conocimientos? Por razones prácticas, a veces conviene «crear» algo para gozar de credibilidad, con el fin de promover estrategias útiles, y con ello para solucionar problemas. Esto lleva, entre otras cosas, a acuñar o inventar términos, con frecuencia sin necesidad alguna, sea porque

$\Pi$ A. P.R. Howatt, A History of English Language Teaching (Oxford: Oxford University Press, 1984);

L. G. Kelly, Twenty-Five Centuries of Language Teaching (Rowley, MA: Newbury House, 1976). 
ya existe una noción plenamente establecida, o porque resulta artificiosa la propuesta. Y si seguimos el hilo de la madeja, podemos dar ya no solo con palabras nuevas aquí y allá, sino también con «nuevas corrientes», muy parecidas a simples modas. ¿Y lo hecho en el pasado?; ¿se habrá tenido el cuidado indispensable de revisar que lo que hemos «creado» o «inventado» no existía ya? Como se dice coloquialmente en nuestro medio, no vaya a ser que descubramos el agua tibia, solo que con otro nombre. Hay un riesgo mayor: el olvido del saber acumulado, o su suplantación con nuevas nomenclaturas, a veces abstrusas. Concebir el pasado como si en la práctica no existiese es una forma de negar la cultura y negar la historia. También, para lo que aquí nos concierne, desentendernos de los avances en lingüística aplicada, tal como hoy la nombramos, sería negar nuestra propia condición de seres históricos. Nada se empieza de cero, a estas alturas de nuestras civilizaciones. Actualmente no se privilegia, como sí ocurría en otras épocas o en otros lugares, el pasado, tal vez porque ese pasado no se conoce lo suficiente.

Si consultamos la denominada bibliografía de referencia, suele afirmarse que la Lingüística Aplicada se desarrolló durante el siglo $\mathrm{xx}$, pero si en escritos de siglos previos encontramos textos que aluden a situaciones semejantes a las que se analizan actualmente, situaciones de las que se ocupa la Lingüística Aplicada, ¿por qué vamos a excluir esos textos del desarrollo de la historia de la Linguística Aplicada solo porque se dieron o se discutieron en el pasado, y se analizaron utilizando otros términos. En el mundo de la matemática, se les reconoce el necesario crédito a los grandes maestros clásicos, y para que sean comprensibles para los matemáticos actuales, simplemente se «traducen» las ecuaciones utilizando los sistemas actuales de notación matemática. Siguen formando parte de la historia de la ciencia. A nadie en su sano juicio se le ocurriría afirmar que no existía la matemática solo porque el sistema de apuntar los cálculos era distinto. Es esencial conocer a fondo los avances equivalentes en nuestra especialidad; «traducir», si se quiere, esos conocimientos 
al uso actual, a modo de punto de partida para construir y propiciar nuevos avances. Pensando hacia el futuro, ¿que sentido tendría abandonar o pasar por alto lo alcanzado hasta hoy en nuestra disciplina? Y esto debería abarcar los estudios menos formales sobre el lenguaje, los manuales o libros de texto, por ejemplo. Tal y como lo ha señalado Sorensen, una de las razones por las cuales tenemos una concepción tan limitada de la metodología empleada en siglos anteriores, es porque no se han tenido en cuenta todos los distintos tipos de materiales existentes ${ }^{12}$.

No podemos soslayar, ya para ir recapitulando esta conversación con ustedes, un tema actual e inmediato: el papel de las nuevas posibilidades de la tecnología contemporánea, en la que con tanta frecuencia ciframos nuestra confianza y casi nuestra fe. Me refiero, como es casi de suponer, al desarrollo a lo largo de los últimos tres decenios de la informática, tanto en nuestra actividad cotidiana, como en el ejercicio de esta disciplina y esta profesión que nos ha conjuntado hoy. Señalo, entre tantas posibilidades que nos da ese instrumento tecnológico, lo que puede hacerse para la elaboración de material y los denominados hoy día «cursos en línea»; destaco también esa tecnología como herramienta, para el análisis automático de textos. El análisis lingüístico asistido por programas de computación tendrá frutos importantísimos para la enseñanza de lenguas maternas y extranjeras puesto que con la información que arroja se contará con una base muy fiable para los cursos y los libros de texto. Se dispondrá de análisis de grandes conjuntos de textos auténticos como punto de partida para lo que se enseña. Pensemos en el avance que se ha dado el ámbito de la Lexicografía y la Terminología. Durante los siglos xviii y xix, la elaboración de un diccionario o de un glosario dependía en gran parte del lexicógrafo y de su destreza y conocimientos individuales para redactar ejemplos; o en el mejor de los casos contaba con un reducido grupo de colaboradores para la

12 Louise Sorensen, Teach Yourself? Language Learning Through Self-Instruction Manuals in Nineteenth Century Scandinavia (Sheffield: University of Sheffield, 2010) 2. 
preparación de fichas. Eso ya está muy lejos de las opciones contemporáneas para desarrollar un diccionario preparado conforme al uso real de una inmensa base de datos compuesta por millares de textos auténticos de distintos temas, fuentes e índoles.

Ante la escasa extensión de su territorio, Costa Rica tiende a mirar hacia afuera en busca de soluciones a sus requerimientos tecnológicos, financieros, comerciales, industriales, pero también a los educativos y a los lingüísticos. Es esencial, por lo tanto, conocer la índole y grado de desarrollo del conocimiento en otras regiones del planeta, pero visto sin cautela y realismo, esto puede conducir a preferir un libro importado, simplemente por serlo, en perjuicio del valor que merece a la producción, intelectual y material, de nuestro medio; como resultado, se mengua la iniciativa interna. Como parte de este fenómeno, nos damos cuenta de la importancia que se da a la promoción de material bibliográfico. Nosotros mismos, pese a las carencias que tenemos, nos vemos en la necesidad de adquirir bibliografía reciente, y en no pocos casos se trata de obras que a fin de cuentas resultan ser reimpresiones con nuevas portadas.

¿Qué lecciones nos dejan las situaciones aquí expuestas? Para empezar, hemos de reconocerles el merecido valor a nuestras propias iniciativas. Eso sí, tener noticia de lo que se está haciendo en todo el planeta, para no reinventar la rueda, pero que la utilidad de la rueda lleve al carro por buen camino y a salvo de tropiezos. Para nuestro caso, dejar que la lingüística aplicada corra por los senderos nuevos y abiertos, segura de que los instrumentos de los que se vale son los apropiados.

Propongamos aquí una lingüística aplicada abarcadora, y por tanto no excluyente; abarcadora conceptualmente, en el espacio y en el tiempo. La exclusión y la sobreespecialización nos llevan al desconocimiento y, más grave aún, al desalojo de otras áreas afines. Una lingüística aplicada integradora y flexible permitiría retomar los conocimientos olvidados del pasado, reconocería y aprovecharía lo que se desarrolla en distintos lugares del planeta, y haría posible 
incorporar en nuestros estudios y en nuestros quehaceres todo lo que puede enriquecer lo que hacemos.

Durante el siglo xx se rechazaron o se promovieron sucesivamente métodos o enfoques para el análisis lingüístico y para la enseñanza de idiomas; modelo tras modelo se introdujeron y se abandonaron a favor del siguiente. En algunos casos, según ciertos métodos se prohibía usar la lengua materna; pero ¿cómo explicar entonces conceptos abstractos que les podrían ser útiles a estudiantes principiantes de un idioma, si también sabemos que no es hasta que tengan un dominio avanzado que pueden utilizar ese idioma para analizar estos asuntos abstractos?

Así podríamos seguir conversando durante horas y horas. Pero eso es mejor dejarlo para las jornadas que nos esperan en esta semana. Volvamos al poema que cité al principio; volvamos a las preguntas que Rubén Darío se hacía, seguramente en un momento de tribulación e incertidumbre. No es el caso nuestro, afortunadamente; ni estamos atribulados ni angustiados, aunque sí asediados por muchas interrogantes y dudas sobre el presente y el futuro de una disciplina a la que, pensándolo bien, nos debemos. ¿Adónde vamos y de dónde venimos? Y añadamos, estimables colegas: ¿dónde estamos en el tiempo, en el espacio, en lo conceptual y en lo disciplinario? Dicho de otro modo: tengamos en mente que estamos en la historia, en la razón científica y en la búsqueda de procedimientos para crear nuevos saberes.

No guardo duda alguna de que para el futuro se requieren definiciones amplias en torno al quehacer académico; en el campo nuestro y en los demás. No caben aquí ni las imposiciones ni los dogmas, sino el esfuerzo por buscar nuevas respuestas, a partir de nuestras propias exploraciones. Puede que entonces sí podamos responder hacia adónde vamos, pero es seguro que también para entonces sabremos de dónde hemos venido. 